\title{
KONDISI GEOLOGI LOKAL KOTA BENGKULU BERDASARKAN GROUND SHEAR STRAIN (GSS)
}

\author{
Nanang Sugianto ${ }^{1,}$ a), M. Farid, Suhendra \\ Program Studi Fisika FMIPA Universitas Bengkulu, Jln. WR. Supratman, Kandang Limun, Bengkulu 38371 \\ Email: ${ }^{\text {a) }}$ nanangsugiantosugi@gmail.com
}

\begin{abstract}
Abstrak
Kondisi geologi lokal merupakan salah satu parameter yang mempengaruhi tingkat kerusakan akibat gempabumi. Kondisi geologi kota Bengkulu telah digambarkan oleh nilai Ground Shear Strain (GSS) yang diperoleh dari hasil analisis enam puluh tujuh data mikrotremor yang dipasang di setiap jenis formasi geologi. Berdasarkan hasil analisis, nilai GSS kota Bengkulu relatif heterogen meskipun pada jenis formasi geologi yang sama. GSS kota Bengkulu diperoleh dan dibagi dalam tiga kelompok, diantarany $10^{-6}(25.37 \%), 10^{-5}(40.30 \%)$ dan $10^{-4}(32.84 \%)$. Variasi ini mengindikasikan adanya perbedaan ketebalan lapisan sedimen dan tingkat kekerasan batuan untuk setiap titik amat. Wilayah yang memiliki nilai GSS tinggi memiliki kesesuaian dengan kondisi lapangan yang sebenarya (berdasarkan hasil ground survey merupakan daerah bekas rawa dengan mofologi landai) dan kesesuaian dengan sejarah kerusakan akibat gempabumi besar di kota Bengkulu. Berdasarkan peta sebaran nilai GSS, potensi deformasi paling tinggi terindentfikasi di bagian barat Kota Bengkulu yaitu wilayah dengan formasi geologi undak alluvium, alluvium dan sebagian formasi andesit, sedangkan formasi geologi lainya relatif lebih aman. Dinamika lapisan tanah permukaan kota Bengkulu umumnya bersifat elastis dan berpotensi mengalami rekahan dansettlement. Struktur geologi yang relatif lunak dan lapisan sedimen yang tipis memungkinkan terjadinya penguatan efek gelombang dan resonansi tinggi ketika gempabumi terjadi.
\end{abstract}

Kata-kata kunci: Kondisi geologi lokal kota Bengkulu, Ground Shear Strain, deformasi.

\begin{abstract}
Local geology condition has become one of the most parameters which affected damage level of earthquake. Geology condition of Bengkulu city has been described by Ground Shear Strain (GSS) value that obtained by sixty seven microtremor data analysis result what instaled on each geology formation types. According analysis result, GSS value of Bengkulu city was heterogeneous relatively in spite of similar geology formation type. GSS in Bengkulu City has obtained and be divided to three category, including $10^{-6}(25.37 \%), 10^{-5}(40.30 \%)$ and $10^{-4}(32.84 \%)$. These variations indicate differences in the thickness of sediment layer and rock solidity level of sites. The Areas of high value of GSS have compatibility with actual field conditions (Based on ground survey, it was swamp area and morphology ramps relatively) and have compatibility with damaged earthquake effect history of Bengkulu city. According map of GSS value distributions, high potency of deformation was indicated in western of Bengkulu city area, it was alluvium terraces formation, alluvium formation and partial of andesite formation, while others were relatively safer. The dynamic characteristic of surface soil layer on Bengkulu city was elastic and potential crack and settlement.The soft geology structure relatively and thin of sediments layer would affected amplification of wave and high resonance when earthquake occur.
\end{abstract}

Keywords: Local geology condition of Bengkulu city, ground shear strain, deformation of soil 


\section{PENDAHULUAN}

Sebaran tingkat kerusakan akibat gempabumi di kota Bengkulu bersifat variatif meskipun jarak terhadap episenter dan magnitudo gempa relatif sama. Fenomena ini membuktikan bahwa selain parameter magnitudo dan jarak episenter, ada parameter lain yang mempengaruhi tingkat kerusakan akibat gempabumi yaitu struktur bangunan dan kondisi geologi lokal. Pada umumnya kualitas struktur bangunan di kota Bengkulu relatif samac, sehingga diduga kondisi geologi lokal memiliki pengaruh signifikan terhadap tingkat kerusakan akibat gempabumi. Hal tersebut dibuktikan pula oleh beberapa peneliti yang menerangkan bahwa karakteristik seismogram berubah mengikuti jenis batuan geologi permukaan. Perbedaan karakteristik tersebut diestimasikan adanya variasi komposisi batuan, tingkat kesolidan batuan dan ketebalan lapisan sedimen setiap titik yang diamati.

Salah salah satu parameter yang dapat menggambarkan kondisi fisis geologi lokal terhadap deformasi adalah Ground Shear Strain (GSS).GSS diperoleh dari hubungan matematis antara indeks kerentanan seismik $\left(K_{g}\right)$ dengan percepatan getaran tanah maksimum $(P G A)$ di batuan dasar. Indeks kerentanan seismik adalah parameter yang menggambarkan kerentanan suatu batuan terhadap getaran sedangkan $P G A$ menggambarkan probabilitas gerakan maksimum yang terjadi pada titik amat tersebut. Indeks kerentana seismik diperoleh dari kuadrat faktor amplifikasi $\left(A_{0}\right)$ dibagi dengan nilai frekuensi resonansi getaran tanah $\left(f_{0}\right)$, dimana $\left(A_{0}\right)$ dan $\left(f_{0}\right)$ diperoleh dari spektrum mikrotremor atau sering disebut kurva HVSR (Horizontal to Vertical Spectral Ratio) dan PGA di batuan dasar ditentukan dengan formula matematis oleh Fukusima-Tanaka.

\subsection{Tatanan Tektonik dan Formasi Geologi Kota Bengkulu}

Secara tektonik, Kota Bengkulu adalah kota yang berada di pesisir pulau yang terbentuk di wilayah subduksi (Gambar 1.a) yaitu penujaman lempeng Indo-Australia terhadap lempeng Eurasia $[1 ; 2]$. Gempabumi di zona ini lebih dikenal dengan zona megathrust dengan sudut kemiringan subduksi yang kecil 10-20 meter hingga kedalaman $30 \mathrm{~km}$ (Gambar 1.b). Baru-baru kota Bengkulu digoncang gempabumi dengan magnitudo 5,9 SR, kedalaman $16 \mathrm{~km}$ dan jarak episenter $61 \mathrm{~km}$ berada di bagian barat daya Bengkulu [3]. Jarak epicenter gempabumi ini tergolong dekat, magnitude tergolong besar, dan menyebabkan kerusakan bangunan.

Kota Bengkulu memiliki 6 jenis formasi geologi[4], yaitu alluvium (Qa), Reef limestone (Q1), swamp deposits (Qs), Alluvium terraces (Qat), andesit (Tpan) and bintunan formation (QTb),seperti yang ditunjukkan pada Gambar 1.c. Secara administrasi, penduduk kota Bengkulu terbanyak terdapat dibagian barat kota Bengkulu dan berada diatas fomasi alluvium terraces (Qat) dan alluvium (Qa), warna hijau dan biru muda pada peta. Berdasarkan sejarah kegempaan, kerusakan terparah akibat gempabumi 2000 dan 2007 atau beberapa tahun yang lalu terindentifikasi dibagian barat kota Bengkulu, dimana lokasi ini adalah wilayah dengan pemukiman padat penduduk dan berada diatas formasi Qat dan Qa. Fenomena ini menunjukkan adanya perbedaan sifat fisis pada masing-masing formasi geologi. 

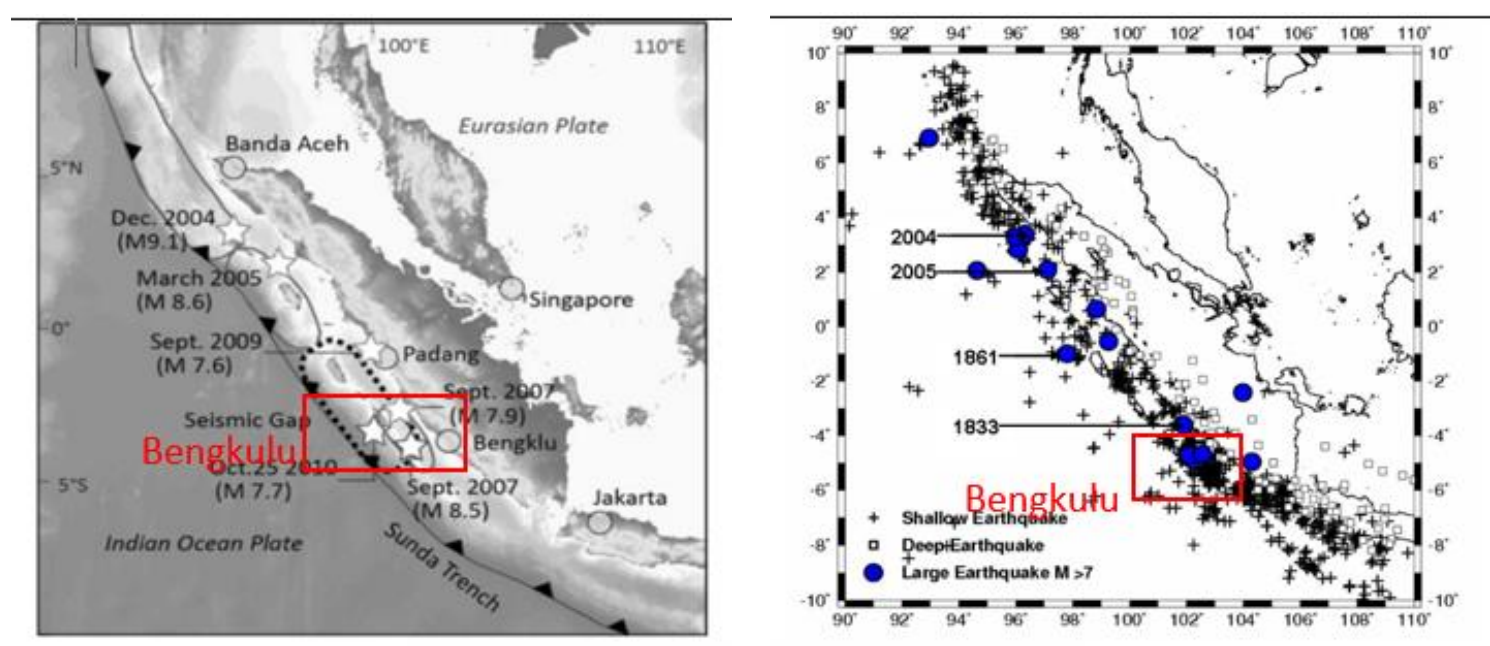

(a)

(b)

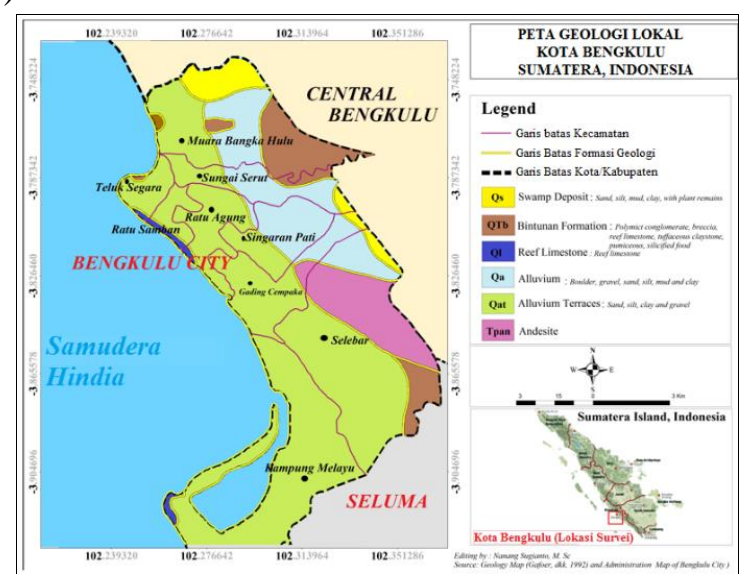

(c)

GAMBAR 1. Tatanan tektonik, Gempabumi Sumatera dan Bengkulu. (a). kondisi tektonik dan gempabumi di bagian barat pulau Sumatera [5]. (b). Peta seismisitas daerah Sumatera [6]. (c). Peta geologi local kota Bengkulu [4]. Kotak merah menunjukkan daerah Kota Bengkulu.

\subsection{Tingkat kerusakan dan Analisis mikrotremor}

Tingkat kerusakan akibat gempabumi tidak hanya tergantung pada jarak episenter dan magnitude, tetapi juga bergantung pada kondisi geologi lokal [7]. Intensitas kerusakan tinggi akibat gempabumi biasanya terjadi pada lokasi dengan pola mikrotremor dengan frekuensi resonansi rendah dan puncak spektrum tinggi. Frekuensi resonansi dan puncak spectrum merupakan respon fisis minimum dari suatu batuan geologi permukaan ketika dikenai oleh getaran. Beberapa peneliti menunjukkan bahwa respon setiap jenis batuan geologi berbeda-beda ketika dikenai oleh gelombang seismik, hal ini ditunjukkan dengan adanya perubahan karakteristik seismogram mengikuti jenis batuan geologi [8; $9 ; 10]$. Fenomena semacam ini dikenal sebagai local site effect yang terjadi akibat adanya kontras impedansi antara lapisan material sedimen halus diatas batuan dasar [11]. Skenaria local site effect ditunjukkan pada Gambar 2 yang menunjukkan pada lapisan sedimen permukaan terjadi multirefleksi gelombang seismik terhadap batuan dasar dibawahnya [12]. 


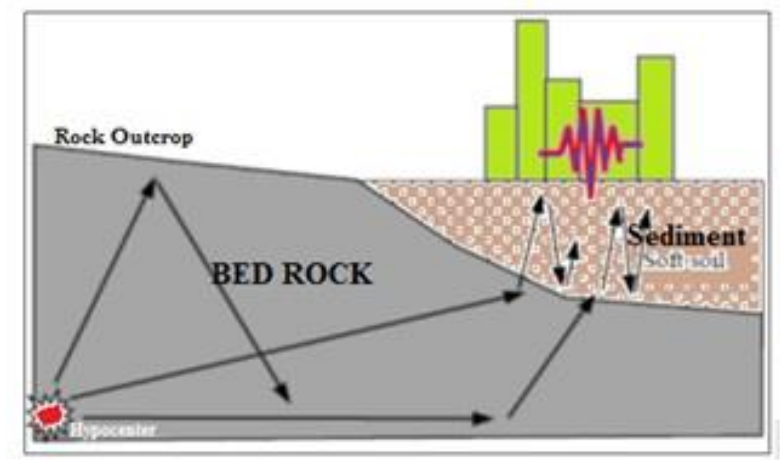

GAMBAR 2. Ilustrasi gelombang seismik yang terjebak dan mengalami multirefleksi di dalam lapisan sedimen [12].

Mikrotremor didasarkan pada perekaman ambient noiseyang dapat digunakan untuk menentukan parameter karakteristik dinamika tanah[13]. Sehingga berdasarkan fungsinya, analisis data mikrotremor mampu menggambarkan kondisi geologi lokal di suatu daerah yang ditunjukkan oleh nilai amplifikasi dan frekuensi dominan suatu batuan terhadap getaran. Nilai amplifikasi dan frekuensi dominan diperoleh dari analisis data mikrotremor dengan menggunakaan metode Horizontal to Vertical Spectral Ratio (HVSR). Metode HVSR didasarkan pada perbandingan spektral amplitudo komponen horizontal terhadap komponen vertikal.

$$
H V S R=\sqrt{\frac{H_{E}^{2}+H_{N}^{2}}{V_{Z}}}
$$

dengan $H_{E}$ dan $H_{N}$ adalah spektrum komponen horizontal North-South dan East- West. Sedangkan $V_{Z}$ adalah komponen vertikal [14].

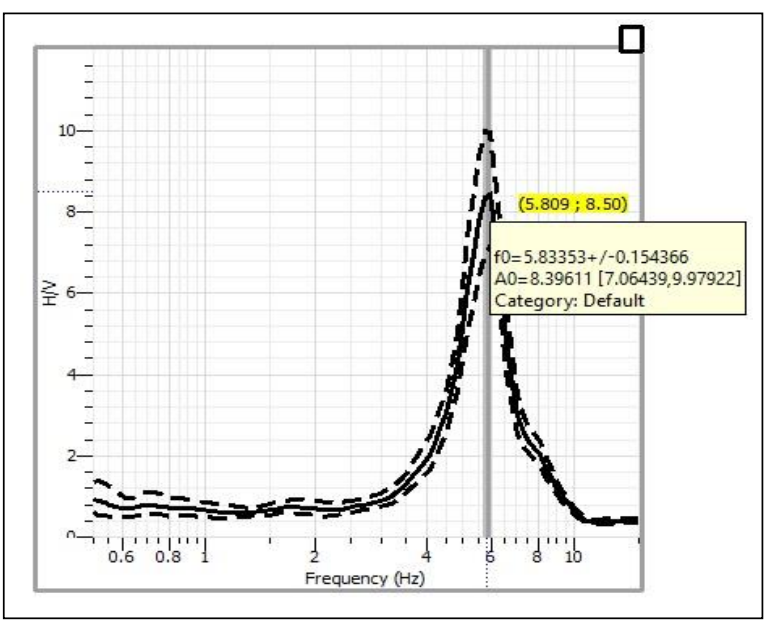

GAMBAR 3. Contoh spektrum mikrotremor hasil analisis HVSR data mikrotremor

\subsection{Ground Shear Strain (GSS)}

Ground shear strain pada lapisan tanah permukaan adalah parameter yang menunjukan tinggi atau rendahnya kemampuan suatu material pada lapisan tanah untuk saling meregang atau bergeser saat terjadi gempabumi $[14 ; 15 ; 16]$. Tinggi atau rendahnya kemampuan material pada lapisan tanah untuk saling meregang atau bergeser tergantung pada kondisi lapisan geologi lokal di suatu daerah. Ground shear-strain lapisan tanah permukaan dapat diperoleh dengan mengalikan antara indeks kerentanan seismik berdasarkan mikrotremor dengan percepatan di batuan dasar $[14 ; 15 ; 16]$ seperti yang diberikan pada Persamaan 2. 
Dengan:

$$
\gamma=k_{g} \times \alpha \times 10^{-6}
$$

$$
K_{g}=\frac{A_{0}^{2}}{f_{n}}
$$

Dan,

$$
\log \alpha=0,41 M-\log \left(R+0,032 \times 10^{0,41 M}\right)-0,0034 R+1,30
$$

dengan $y=$ Ground shear strain $(G S S), \mathrm{K}_{\mathrm{g}}=$ Indeks Kerentanan seismik, $A_{0}=$ Faktor Amplifikasi Tanah. $f_{0}=$ Frekuensi Dominan Tanah $(\mathrm{Hz}), M=$ Magnitudo gempa, $R=$ Jarak stasiun rekaman terhadap episenter, $\alpha=$ percepatan getaran tanah maksimum di batuan dasar (menggunakan persamaan Fukusima dan Tanaka (1990)), dan $10^{-6}=$ merupakan ketetapan untuk memperkirakan nilai strain pada lapisan tanah permukaan.

Lapisan tanah permukaan akan bersifat plastis pada nilai $\gamma=1.000 \times 10^{-6}$, sedangkan pada $\gamma>10.000 \times 10^{-6}$ lapisan tanah dapat mengalami deformasi [17]. Gempabumi merusak biasanya terjadi bilamana batas ground shear-strainterlampaui, sehingga terjadi deformasi lapisan tanah. Hubungan

\begin{tabular}{|c|c|c|c|}
\hline Size of Strain & $10^{-6} 10^{-5}$ & $10^{-4} 10^{-2}$ & $10^{-1}$ \\
\hline Phenomena & Wave, Vibration & Crack, Settlement & $\begin{array}{c}\text { Landslide, Soil Compaction, } \\
\text { Liquefaction }\end{array}$ \\
\hline $\begin{array}{l}\text { Dynamic } \\
\text { Properties }\end{array}$ & Elasticity & Elasto-Plasticity & $\begin{array}{l}\text { Repeat-effect, Speed effect of } \\
\text { loading }\end{array}$ \\
\hline
\end{tabular}
antara ground shear strain dengan sifat dinamik tanah dapat dilihat pada Tabel 1.

TABEL 1. Hubungan Nilai Ground Shear Strain dengan sifat dinamika tanah [17]

\section{METODOLOGI PENELITIAN}

Data mikrotremor direkam menggunakan seismometer digital yang didistribusikan di setiap jenis formasi geologi kota Bengkulu sebanyak 67 stasiun. Nilai GSS diperoleh melalui hitungan matematis perkalian antara indeks kerentanan seismik, PGA di batuan dasar dan nilai ketetapan untuk memperkirakan nilai strain. Nilai indek kerentanan seismik diperoleh dari kuadratik fakto amplifikasi A0dibagi frekuensi dominan f0 yang diperoleh dari kurva analisis HVSR. Nilai PGA di batuan dasar diperoleh menggunakan formula FukusimaTanaka (Persamaan 4) dengan data histori gempa besar dibengkulu sejak tahun 2000 hingga 2015 yang diperoleh dari BMKG. Hasil pengolahan data diinterpretasikan kedalam peta sebaran nilai Ground Shear Strain di setiap jenis formasi geologi Kota Bengkulu. Wilayah yang memiliki nilai GSS tinggi diasumsikan rentan mengalami deformasi ketika gempabumi terjadi, sedangkan wilayah dengan nilai GSS rendah diasumsikan memiliki potensi kecil terhadap deformasi dan diestimasikan relatif lebih aman. Kemudian hasil observasi secara numeric ini akan di sesuaikan dengan hasil pengamatan lapangan secara langsung dan visual yang digunakan untuk menggambarkan kondisi geologi permukaan yang sebenarnya.

\section{HASIL DAN PEMBAHASAN}

Ground Shear Strain (GSS) merupakan parameter fisis yang dapat menggambarkan besar kecilnya deformasi permukaan tanah yang mungkin terjadi ketika gempabumi. Probabilitas deformasi permukaan tanah bergantung pada kondisi geologi lokal di wilayah tersebut. Karakteristik struktur batuan, ketebalan lapisan sedimen dan komposisi material penyusun batuan adalah parameterparameter yang menjelaskan kondisi geologi lokal. Distribusi nilai GSS kota Bengkulu bervariasi meskipun pada jenis formasi geologi yang sama. Secara umum nilai GSS kota Bengkulu dbagi ke dalam tiga kategori, yaitu $1 \times 10^{-6}$, $1 \times 10^{-5}$, dan $1 \times 10^{-4}$. Dari ketiga kategori ini diestimasikan $32.84 \%$ 
dari luasan kota Bengkulu berpotensi mengalami deformasi permukan tanah berupa rekahan dan settlementdan $67.16 \%$ dari luasan kota Bengkulu berpotensi mengalami goncangan akibat gelombang dan getaran akibat gempabumi. Data hasil observasi secara detail diberikan oleh Tabel 2.

TABEL 2. Ground Shear Strain, sifat dinamika tanah dan fenomena yang mungkin terjadi di Kota Bengkulu

\begin{tabular}{|c|c|c|c|c|c|}
\hline \multirow{2}{*}{ Nilai GSS } & \multirow{2}{*}{$\begin{array}{l}\text { Kategori } \\
\text { nilai }\end{array}$} & \multirow{2}{*}{$\begin{array}{c}\text { Persentase } \\
\text { luasan }\end{array}$} & \multirow{2}{*}{ Jenis Formasi } & \multicolumn{2}{|c|}{$\begin{array}{c}\text { Hubungan Nilai GSS dengan sifat } \\
\text { dinamika tanah }\end{array}$} \\
\hline & & & & Fenomena & $\begin{array}{c}\text { Sifat } \\
\text { Dinamika }\end{array}$ \\
\hline $0.61-9.96$ & $1 \times 10^{-6}$ & $25.37 \%$ & $\begin{array}{c}\text { Tpan, dan sebagian } \\
\text { Qa dan Qat }\end{array}$ & Wave, Vibration & Elasticity \\
\hline $10.45-89.52$ & $1 \times 10^{-5}$ & $40.30 \%$ & $\begin{array}{l}\text { Tpan, Qat, Qa, } \\
\text { QTb, Qs dan Q1 }\end{array}$ & Wave, Vibration & Elasticity \\
\hline $101.51-477.59$ & $1 \times 10^{-4}$ & $32.84 \%$ & $\begin{array}{c}\text { Sebagian Besar Qat } \\
\text { dan sebagian Qa } \\
\text { dan Tpan }\end{array}$ & Crack, Settlement & $\begin{array}{c}\text { Elasto- } \\
\text { Plasticity }\end{array}$ \\
\hline
\end{tabular}

Tabel 2 merupakan hasil observasi secara umum yang menggambarkan kondisi geologi di setiap jenis formasi geologi kota Bengkulu berdasarkan nilai Ground Shear Strain. Berdasarkan tabel diatas, kota Bengkulu berpotensi mengalami rekahan seluas 32,84\% dari luasan kota Bengkulu. Lokasi potensi ini tersebar cukup acak di tiga jenis formasi geologi, yaitu Qat, Qa dan Tpan. Pada ketiga batuan ini memiliki sifat dinamika elasto-plasticity Sedangkan wilayah yang lainnya hanya akan berpotensi mengalami goncangan akibat gempabumi dan getaran. Secara detail distribusi nilai GSS di kota Bengkulu ditunjukkan pada Gambar 4.



GAMBAR 4. Distribusi Nilai Ground Shear Strain (GSS) di kota Bengkulu. Nilai GSS kota Bengkulu dibagi ke dalam tiga Kategori. Kontur berwarna merah merupakan daerah yang berpotensi mengalami rekahan.

Nilai Ground Shear Strain bergantung pada respon amplifikasi dan frekuensi dominan getaran tanah yang diperoleh dari hasi analisis kurva HVSR data Mikrotremor. Perbedaan respon tersebut ditunjukkan adanya perubahan karaktristik seismogram setiap titik pengamatan. hubungan faktor ampifikasi dan frekuensi dominan ini digambarkan oleh Indek Kerentanan Seismik $\left(K_{g}\right)$ yang 
merupakan kerentanan suatu batuan terhadap deformasi. Nilai PGA batuan dasar di Kota Bengkulu umumnya sama yaitu rata-rata 45 gal. nilai. Kecilnya variasi nilai PGA batuan dasar di setiap titik amat menunjukkan kecilnya luasan wilayah pengamatan, sehingga nilai GSS sangat bergantung dengan respon amplifikasi dan frekuensi resonansi lapisan tanah permukaan terhadap getaran.

Nilai faktor amplifikasi lapisan tanah permukaan yang besar terindentifikasi pada stuktur batuan yang lunak dan lapisan sedimen yang tebal yaitu ditunjukkan dengan nilai indek kerentanan seismik yang tinggi. Nilai PGA di batuan dasar yang relatif sama, nilai GSS sangat bergantung pada nilai indek kerentanan seismik. Nilai GSS yang tinggi terindentifikasi pada wilayah yang memiliki struktur yang relatif lunak dan memiliki lapisan sedimen yang tebal. Sebaliknya nilai GSS tinggi terindentifikasi pada wilayah yang memiliki struktur lapisan tanah yang relatif solid dan memiliki lapisan sedimen yang tipis.

Berdasarkan hasil observasi secara visual ditemukan bahwa, daerah yang memiliki nilai GSS tinggi umumnya daerah bekas rawa. Daerah bekas rawa merupakan daerah yang memiliki struktur batuan yang relatif lunak dan lapisan sedimen yang tebal (Sugianto, 2016). Sedangkan nilai GSS rendah terindentifikasi pada daerah yang memiliki struktur lapisan tanah permukaan yang relatif keras. Validasi ini ditemukan adanya kecocokan diantara keduanya. Selain itu hasil dari observasi ini bersesuaian pula dengan sejarah besaran efek gempabumi merusak di kota Bengkulu, yaitu hancurnya bangunan, rekahan tanah, amblesan dan banyak efek-efek lainnya yang disebabkan oleh gempabumi khusunya gempabumi tahun 2000 dan gempabumi tahun 2007. Wilayah yang memiliki nilai GSS rendah diestimasikan lebih aman dari efek gempabumi merusak, sedangkan wilayah yang memiliki nilai GSS tinggi diestimasikan lebih rawan terhadap gempabumi merusak di Kota Bengkulu. melalui hasil ini dapat dijadikan pertimbangan oleh pemerintah sebagai salah satu langkah pengurangan risiko gempabumi bumi di Kota Bengkulu.

\section{SIMPULAN}

Nilai GSS kota Bengkulu relatif heterogen meskipun pada jenis formasi geologi yang sama. GSS kota Bengkulu diperoleh dan dibagi dalam tiga kelompok, diantarany $10^{-6}(25.37 \%), 10^{-5}(40.30 \%)$ dan $10^{-4}(32.84 \%)$. Variasi ini mengindikasikan adanya perbedaan ketebalan lapisan sedimen dan tingkat kekerasan batuan untuk setiap titik amat. Nilai GSS yang tinggi terindentifikasi pada wilayah yang memiliki struktur yang relatif lunak dan memiliki lapisan sedimen yang tebal. Sebaliknya nilai GSS tinggi terindentifikasi pada wilayah yang memiliki struktur lapisan tanah yang relatif solid dan memiliki lapisan sedimen yang tipis. Kondisi ini bersesuaian dengan hasil pengamatan secara visual, yaitu daerah yang memiliki nilai GSS tinggi merupakan daerah bekas rawa yang secara histori pernah mengalami efek gempa merusak dan terjadi rekahan tanah permukaan saat gempbumi.

\section{UCAPAN TERIMAKASIH}

Terimakasih kepada semua tim penelitian Geofisika, Program Studi Fisika FMIPA UNIB yang terlibat dalam penelitian.

\section{DAFTAR ACUAN}

[1] Hantoro, W. S. 2002. Pengaruh Karakteristik Laut Dan Pantai Terhadap Perkembangan Kawasan Kota Pantai. Pusat Penelitian Geoteknologi LIPI. Bandung.

[2] Natawidjaja D.H., Sieh, K., Galetzka, J., Suwargadi, B., Cheng, H., and Edwards, R. 2007. Interseismic deformation above the Sunda Megathrust recorded in Coral Microatolls of the Mentawai Islands, West Sumatera: J. Geophys. Res.

[3] BMKG. 2016. Informasi Gempa Terkini Indonesia. www.bmkg.co.id. Diunduh 11 April 2016. 
[4] Gafoer, T.C dan Pardede R. 1992. Geology of the Bengkulu Quadrangle, Sumatera. Geological research and Development Center: Indonesia

[5] Satake K, Nishimura, Y, Putra P.S, Gusma, A.R, Sunendar, H. Fujji, Y, Tanioka, Y. Latief H, Yulianto, E. 2012. Tsunami Source of the Mentawai, Indonesia Earthquake Inferred from Tsunami Field Survey and Waveform Modeling. Pure Appl. Geophys. 17(2013), 1567-1582.

[6] Puspito. N.T dan Gunawan I. 2005. Tsunami Sources In the Sumatera Region, Indonesia and Simulation of the 26 December 2004 Aceh Tsunami. ISET Journal of Earthquake Tecnology, paper No. 459,Vol. 42, No.4, December 2005, pp. 111-125.

[7] Naeni, S. A and Zarincheh, A. 2010. Site effects and seismic hazard analysis of Kermanshah Region of Iran. Journal of Applied Science 10 (19): 2231-2240.

[8] Daryono. 2013. Indeks Kerentanan Seismik Berdasarkan Miktrotremor pada Setiap Satuan Bentuk Lahan di Zona Graben Bantul Daerah Istimewa Yogyakarta. Jurnal Riset Daerah XII (1): 1754-1777.

[9] Improta L., Giulio, G.D., and Rovelli, A. 2005. Variation of local sismic response in Benevento (Southerm Italy) using earthquakes and ambient noise recordings. Journal of Seismology, 9: 191-210.

[10] Singh, S.K., Ordaz, M. and Pacheco, J.F. 2003. Advanced in Seismology with Impact on Earthquake. International Handbook of Earthquake and Engineering Seismology, Volume 81.

[11] Zaharia, B., Radulian, M., Popa, M., Grecu, B., Bala, A. and Tataru, D. 2008. Estimation of the local response using the Nakamura method for the Bucharest area.Romanian Report in Physics, Vol. 60, No. 1, P. 131-144.

[12] Tuladhar, R. 2002. Seismic microzonation of greather Bangkok using microtremor. Thesis. Asian Institute of Technology, School of Civil Engineering, Thailand.

[13] Mufida, A., Santosa, B.J., Warnana, D.D. 2013. Profiling Kecepatan Gelombang Geser (Vs) Surabaya Berdasarkan Pengolahan data Mikrotremor. Jurnal Sains dan Seni Pomits: Surabaya.

[14] Nakamura, Y. 2008. On The H/V Spectrum. The $14^{\text {th }}$ World Conference on Earthquake Engineering, Beijing, China.

[15] Nakamura, Y. 2000. Clear Identification of Fundamental Idea of Nakamura's Technique and Its Application.World Conference of Earthquake Engineering.

[16] Nakamura, Y., Sato, T., and Nishinaga, M. 2000. Local Site Effect of Kobe Based on Microtremor Measurement. Proceeding of the Sixth International Conference on Seismic Zonation EERI, Palm Springs California.

[17] Isihara, K., 1982, Evaluatian of Soil Properties for Use in Earthquake Response Analysis. Proc. Int. Symp. On Numerical Model in Geomech, 237-259.

[18] Sugianto, N. 2016. Local geology Condition of Bengkulu City Based on Seismic Vulnerability Index. ARPN Journal of Engineering and Applied Sciences. Vol. 11, No. 7, April 2016. ISSN 1819-6608. 